\title{
Solution of distributed generation allocation problem using a novel method
}

\author{
A.Y. Abdelaziz ${ }^{1}$, S.F. Mekhamer ${ }^{2}$, R.H. Shehata ${ }^{3}$ \\ ${ }^{1}$ Faculty of Engineering \& Technology Future University in Egypt, Egypt \\ ${ }^{2}$ Future University in Egypt, Egypt \\ ${ }^{3}$ Electrical Power \& Machines Department, Ain shams university, Egypt
}

\begin{tabular}{l} 
Article Info \\
\hline Article history: \\
Received Nov 13, 2018 \\
Revised Jan 21, 2019 \\
Accepted Mar 11, 2019 \\
\hline Keywords: \\
DG allocation \\
Voltage profile improvement \\
Whale optimization algorithm \\
power loss minimization
\end{tabular}

Article Info

icle history:

\begin{abstract}
In this paper, A novel optimization technique called whale optimization algorithm (WOA) is modified, used and implemented to find the best possible solution to the problem of optimal locating and sizing of Distributed Generation (DG) resources such as photovoltaic cells, fuel cells and kVAR compensators in radial distribution feeders. The modified technique is used for the first time to solve this kind of optimization problem which includes optimal sizing and location of DG units in radial distribution feeder. The proposed method is applied to two different test distribution feeders (15 bus and 33 bus test systems) using different DG types and the acquired results are analyzed and compared to other modern optimization methods to confirm that they give the best results, lowest system real power losses and highest voltage profile improvement among the other modern methods implemented on the same test systems.
\end{abstract}

Copyright (C) 2019 Institute of Advanced Engineering and Science. All rights reserved.

\section{Corresponding Author:}

A.Y. Abdelaziz,

Faculty of Engineering \& Technology,

Future University in Egypt, Cairo, Egypt.

Email: almoatazabdelaziz@hotmail.com

\section{INTRODUCTION}

The current modern electrical power system is one of the most complex systems in the human history. Classical generation power stations are centralized, monitored, built away from human cities and transmitted over thousands of kilometers to the required electrical loads. In the recent decades the electrical power system suffered from different blackouts due to different reasons which affected millions of customers all over the world. To overcome some of modern grid problems which includes but not limited to power losses, outages, blackouts, voltage flickers, harmonics, efficiency, voltage instability and costs decentralized distributed generation (DG) sources are used close to the customers connected or isolated from main electrical grid which provides another solution of providing less polluted electrical energy sources as most of the DG technologies are renewable environmental friendly sources such as photovoltaic systems and wind turbines [1-7]. Another reason for involving DG technologies in some countries is to make a diversity in the companies supplying electricity, thus establishing a competitive electrical market where the customer benefits from different categories and prices of electrical bill. The Department of Energy (DOE) considers the DG as the generation of electricity from the sources which are varying from less than a kilowatt $(\mathrm{kW})$ to tens of megawatts (MW) in size for single distributed generation unit [8]. The merits of placing and installing of distributed generation (DG) units in radial distribution network beside the economic and environmental benefits includes voltage profile enhancement, system total power loss reduction, power quality improvement, strengthen system reliability, protection, increase system stability, system better performance and power flow control [8-9]. It is worth mentioning that the improper sizing and random locating of DG 
units in the power system can lead to increase the active power losses in the distribution system. DG resources can be categorized as mentioned in [10] into four types;

DG type I: capable of injecting active power in $\mathrm{kW}$ and operates at unity power factor. Examples of this type are photovoltaic, fuel cells and micro-turbines.

DG type II: capable of injecting reactive power in kVAR. Reactive power compensators, capacitors and synchronous compensators belong to this type.

DG type III: capable of injecting both active and reactive power in $\mathrm{kW}$ and $\mathrm{kVAR}$ respectively. DG resources depending on synchronous machine as cogeneration are part of this type of distributed generation.

DG type IV: capable of injecting active power in $\mathrm{kW}$ and consuming reactive power in $\mathrm{kVAR}$ at the same time. The obvious example of this type of DG is induction generators used in wind farms.

Many attempts have been done using artificial intelligence (AI) based techniques to optimally size and locate the Distributed Generation (DG) in the distribution systems. The whale optimization algorithm and its modifications belong to the swarm intelligence methods which are a part of the AI based methods. Most swarm intelligence techniques are inspired by the creatures and species in nature.

The application of ant lion optimization algorithm to optimally allocate and size renewable DG technologies (wind turbines and photovoltaic systems) are discussed in [11] where the loss sensitivity factors are used to determine the required candidate buses to connect the DG units. However, it can be noticed that when installing two wind turbines on 33 bus test system to minimize the power loss in $\mathrm{kW}$, the sizes of the DG units used in KVA are bigger than the ones used in [12] on the same test system by $27.7 \%$.

Ref. [13] proposes a meta-heuristic algorithm called invasive weed optimization algorithm to find the optimal sizing of the placed DG and location of the bus where the DG would be installed is determined by loss sensitivity factor. The issue in this study that the reduced total real power loss after placement of the DG is not the optimum compared to other methods applied to the same test systems.

Ref. [14] focused on placement of different DG renewable resources such as wind turbines and PV arrays in radial distribution feeders, the study used type I, type II and type III DGs. The optimization method used to reach the optimal global solution is the whale optimization algorithm WOA with the assistance of power loss index. The introduced technique is tested on small and large test feeders 15 bus, 33 bus, 69 bus, 85 bus and 118 bus test systems. The disadvantage of this work is that the results obtained from testing the 15 bus and 118 bus test systems are not compared with other techniques and methods previously applied to the same test feeders, so the effectiveness of the technique used is not verified. Regarding the 33 bus and 69 bus test systems the technique couldn't reach the optimal voltage profile improvement as for the instance an older method proposed in [15] reached better system voltage profile when applied to the same test feeders.

Ref. [16] introduced a modern optimization technique to approach the solution of the DG allocation and sizing problem in distribution feeders. The stud krill herd algorithm is utilized to get the minimum power losses of the system under study. The algorithm is implemented and tested on 33 bus, 69 bus test systems and the 94 bus Portuguese radial distribution system. The study placed one DG, two DG and three DG to prove the abilities of the technique used. The results show that the algorithm achieved its target to reach lowest possible active power losses in the system at the expense of using larger sizes of placed DG units when compared to other optimization algorithms in references [17-19] applied to the same 33 bus, 69 bus test systems and the 94 bus Portuguese radial distribution feeder studied in the last previous years.

Ref. [20] presented the grey wolf optimizer as a method to solve the problem of optimal locating and sizing of multiple DG units in radial distribution system. The method is implemented on IEEE 69 bus test system to verify its effectiveness and capabilities. The system power losses were enormously reduced with the placement of different DG sizes accompanied by enhancement in the system voltage profile. However, the average elapsed time to converge the optimal solution is higher than other methods applied to the same test system as the bat algorithm and gravitational search algorithm.

In this paper, the modified whale optimization algorithm is applied to three different IEEE radial distribution feeders. This proposed technique is intended to find the optimal solutions to allocate and size DG units (type I, type II and type III) in radial distribution feeders. The algorithm follows a set of predetermined steps to find the global optimal solution to this kind of hard optimization problems. This proposed method is implemented for the first time to solve this kind of optimization problems which includes sizing and locating DG units in any radial distribution feeder. This novel algorithm has the capability to find the optimal solution regarding the lowest system minimum real power losses accompanied by voltage profile improvement without violating the problem constraints such as power conservation boundaries, bus voltage constraints, DG real and reactive power limits and maximum thermal capacity of branch lines constraint.

The rest of the paper is divided as follows: Section 2 presents the traditional whale optimization algorithm and the modifications applied to it to be modified and enhanced. Also, the solution algorithm to implement the modified whale optimization algorithm to the problem of optimal allocation and sizing of 
different DG units in radial distribution feeder is explained in detail. Section 3 presents the implementation and computer based program simulation results compared to other optimization techniques using MATLAB facilities. Finally Section 4 includes the conclusions.

\section{RESEARCH METHOD}

\subsection{Whale Optimization Algorithm (WOA)}

In nature, the real whales spread all over the world in oceans and seas. Scientists studied their way of living and hunting. In Ref. [21, 22], the traditional WOA is a nature inspired meta-heuristic optimization algorithm which mimics the social behaviour of humpback whales. The bubble net hunting method used by humpback whales in hunting its prey such as group of fishes close the surface of the water is utilized by the artificial whales in the proposed algorithm. The method is simple and easy to be implemented. The mathematical model could be described as follow:

A. Search for prey

The first step is exploration phase, in this phase the humpback whales search randomly for the prey, so the variation of vector A is used to represent this searching process. The position update of each whale is done by moving towards a random known search agent, so the global search happens. As shown is (1) and (2) describe the previous behavior:

$$
\begin{aligned}
& \mathrm{D}=\mid \mathrm{C} . \text { Xrand }-\mathrm{X} \mid \\
& \mathrm{X}(\mathrm{t}+1)=\mathrm{Xrand}-\mathrm{A} . \mathrm{D}
\end{aligned}
$$

where

$$
\begin{aligned}
& \mathrm{A}=2 \cdot \mathrm{a} \cdot \mathrm{r}-\mathrm{a} \\
& \mathrm{C}=2 \cdot \mathrm{r}
\end{aligned}
$$

A is coefficient vectors

$\mathrm{C}$ is coefficient vectors

$\mathrm{t}$ is the current iteration

$\mathrm{X}$ is the position vector

a is linear decreasing from 2 to 0

$\mathrm{r}$ is the random number between $[0,1]$

B. Encircling the prey

The location of the prey is recognized by humpback whales which encircle them. The other search agents in the search space change and update their positions towards the defined best search agent. The behavior is described mathematically as follows:

$$
\begin{aligned}
& D=\left|C . X^{*}(t)-X(t)\right| \\
& X(t+1)=X^{*}(t)-A . D
\end{aligned}
$$

where :

$\mathrm{X}^{*}$ is the best value of the position vector

\section{Bubble-net attacking method}

To hunt the prey the humpback whales makes two mechanisms simultaneously which are shrinking circle and moving in spiral path shape to update their position. After determining the distance between the whale and prey, the movement takes place as shown in Figure 1. An assumption is made that the probability to choose between either to shrink encircle or to move in spiral shaped path is $50 \%$, so a variable (p) is introduced to indicate that probability, Another constant is introduced to represent the spiral shape path called (b). The behavior is described by the following equation:

$$
X(t+1)= \begin{cases}X^{*}(t)-A \cdot D & \text { iff } p<0.5 \\ D \cdot e^{b \cdot l} \cdot \cos (2 \cdot \pi \cdot l)+X^{*}(t) & \text { iff } p>0.5\end{cases}
$$


where

(p) is a random number between $[0,1]$.

(l) is random number from $[-1,1]$.

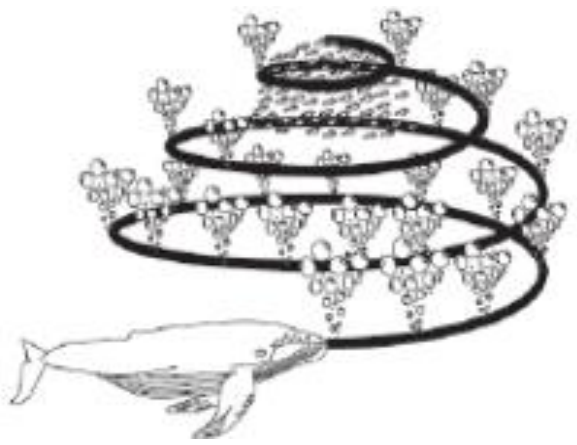

Figure 1. Bubble-net feeding behaviour of humpback whales

\subsection{Modified Whale Optimization Algorithm (MWOA)}

In Ref. [23], procedures are presented in order to modify and enhance the traditional whale optimization algorithm regarding the performance and results obtained. An inertia weight $(\omega) \in[0,1]$ is added to introduce the modified whale optimization algorithm (MWOA), in this case (5) and (6) are modified as follows:

$$
\begin{aligned}
& D=\left|C \cdot \omega X^{*}(t)-X(t)\right| \\
& X(t+1)=\omega X^{*}(t)-\text { A.D }
\end{aligned}
$$

Where:

$(\omega)$ an inertia weight $\in[0,1]$

Also (7) representing the update of the position in the spiral path would be modified as follow:

$$
X(t+1)= \begin{cases}\omega X^{*}(t)-A \cdot D & \text { iff } p<0.5 \\ D \cdot e^{b . l} \cdot \cos (2 \cdot \pi \cdot l)+\omega X^{*}(t) & \text { iff } p>0.5\end{cases}
$$

The modified algorithm steps of the MWOA can be summarized as:

a) Initialize the whales' population $\mathrm{Xi}$ where $\mathrm{i}=(1,2,3, ., \mathrm{n})$ and set the Maxgen (maximum number of iterations). Set $\mathrm{t}=1$.

b) Calculate the fitness value of $\mathrm{Xi}$ where $\mathrm{i}=(1,2,3, \ldots, \mathrm{n})$, identify the best search candidate solution $\mathrm{X}^{*}$.

c) Repeat the following: For every Xi $(\mathrm{i}=1,2,3, \ldots, \mathrm{n})$, update $\mathrm{p}, \mathrm{C}, \mathrm{A}, 1$, a. If $\mathrm{p}<0.5$, then if $|\mathrm{A}|<1$, update the position of the current search agent by (8) and if $|A| \geq 1$, select a random search solution Xrand and update the position of the current search agent by (2). But when $p \geq 0.5$, update the position of the current search by the (10) Check if any search agent goes beyond the known search and modify it. Calculate the fitness of $\mathrm{Xi}(\mathrm{i}=1,2,3, \ldots, \mathrm{n})$, and if there is a better solution, find the best search solution $X^{*}$. Set $t=t+1$. Until $t$ reaches maximum number of iterations, the algorithm is finished.

d) Return the best optimization solution $\mathrm{X}^{*}$ and the best optimization value of fitness values.

\subsection{The Power Flow Calculations}

From [7] and others, Newton Rapshon, fast decoupled load flow, backward forward sweep and Gauss Seidel are some of the most popular methods to solve the load flow problem of radial distribution feeder. In this study, the Newton Raphson technique is used to find the power flow solution for each test feeder. Figure 2 shows the single line diagram of a general radial distribution feeder model. The governing load flow equations used could be stated as follow [24]:

$$
\mathrm{P}_{\mathrm{i}+1}=\mathrm{P}_{\mathrm{i}}-\mathrm{r}_{\mathrm{i}+1}\left(\mathrm{P}_{\mathrm{i}}^{2}+\mathrm{Q}_{\mathrm{i}}^{2}\right) / \mathrm{V}_{\mathrm{i}}^{2}-\mathrm{P}_{\mathrm{Li}+1}
$$




$$
\begin{aligned}
& \mathrm{Q}_{\mathrm{i}+1}=\mathrm{Q}_{\mathrm{i}}-\mathrm{X}_{\mathrm{i}+1}\left(\mathrm{P}_{\mathrm{i}}^{2}+\mathrm{Q}_{\mathrm{i}}{ }^{2}\right) / \mathrm{V}_{\mathrm{i}}{ }^{2}-\mathrm{Q}_{\mathrm{Li}+1+}+\mathrm{Q}_{\mathrm{Ci}+1}(12) \\
& \mathrm{V}_{\mathrm{i}+1}{ }^{2}=\mathrm{V}_{\mathrm{i}}{ }^{2}-2\left(\mathrm{r}_{\mathrm{i}+1} \mathrm{P}_{\mathrm{i}}+\mathrm{X}_{\mathrm{i}+1} \mathrm{Q}_{\mathrm{i}}\right)+\left(\left(\mathrm{r}_{\mathrm{i}+1}{ }^{2}+\mathrm{x}_{\mathrm{i}+1}{ }^{2}\right) *\left(\mathrm{P}_{\mathrm{i}}^{2}+\mathrm{Q}_{\mathrm{i}}{ }^{2}\right)\right) / \mathrm{V}_{\mathrm{i}}{ }^{2} \\
& \mathrm{P}_{\text {lossi+1 }}=\mathrm{r}_{\mathrm{i}+1}\left(\mathrm{P}_{\mathrm{i}}{ }^{2}+\mathrm{Q}_{\mathrm{i}}{ }^{2}\right) / \mathrm{V}_{\mathrm{i}}{ }^{2} \\
& \mathrm{Q}_{\text {lossi }+1}=\mathrm{x}_{\mathrm{i}+1}\left(\mathrm{P}_{\mathrm{i}}{ }^{2}+\mathrm{Q}_{\mathrm{i}}{ }^{2}\right) / \mathrm{V}_{\mathrm{i}}{ }^{2}
\end{aligned}
$$

Where,

$P_{i}$ : active power flows into the sending of branch $i+1$ connecting node $i$ and node $i+1$

$\mathrm{Q}_{\mathrm{i}}$ : reactive power flows into the sending of branch $\mathrm{i}+1$ connecting node $\mathrm{i}$ and node $\mathrm{i}+1$

Vi: bus voltage magnitude at node $\mathrm{i}$

$\mathrm{Q}_{\mathrm{Ci}+1}$ : reactive power injection from capacitor at node $\mathrm{i}+1$

$\mathrm{P}_{\mathrm{Li}+1}$ : active power load connected to node $\mathrm{i}+1$

$\mathrm{Q}_{\mathrm{Li}+1}$ : reactive power load connected to node $\mathrm{i}+1$

$\mathrm{r}_{\mathrm{i}+1}$ : line resistance between node $\mathrm{i}$ and node $\mathrm{i}+1$

$x_{i+1}$ : line reactance between node $i$ and node $i+1$

$\mathrm{P}_{\text {lossi+1: }}$ active power losses of branch connecting node $\mathrm{i}$ and node $\mathrm{i}+1$

$\mathrm{Q}_{\text {lossit1: }}$ reactive power losses of branch connecting node $\mathrm{i}$ and node $\mathrm{i}+1$

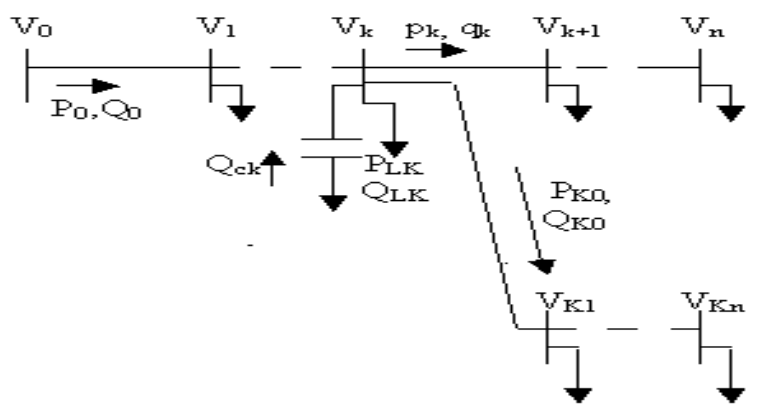

Figure 2. Single line diagram of a model of radial distribution feeder

\subsection{Objective Function}

The purpose of optimal sitting and sizing of DG units in the radial distribution system is to enhance the voltage profile of the system and decrease the real power loss in $\mathrm{kW}$ on condition not to violate the predetermined system constraints. From [17] the optimal solution is to minimize the real power losses which can be stated as:

$$
\text { Minimize } F=\min \left(P_{\text {total loss }}\right)
$$

where

$\mathrm{P}_{\text {total loss }}$ is the total real power losses of distribution network According to the following constraints:

\section{A. Voltage constraints}

$$
\mathrm{Vmin} \leq \mathrm{Vi} \leq \mathrm{Vmax}
$$

where

Vmin: minimum bus voltage limit

Vmax: maximum bus voltage limit

B. Power balance constraint

$$
\mathrm{P}_{\text {loss }}+\mathrm{P}_{\mathrm{d}}=\mathrm{P}_{\text {slack }}+\sum_{\mathrm{k}=1}^{\mathrm{N}} \mathrm{P}_{\mathrm{DG}}
$$


Where,

$\mathrm{P}_{\text {slack }}$ is the slack bus real power

$\mathrm{P}_{\text {loss }}$ is the system power loss in $\mathrm{kw}$

$P_{d}$ is the system load in $\mathrm{kw}$

$\mathrm{P}_{\mathrm{DG}}$ is the power of $\mathrm{DG}$ unit

C. Upper and lower limits of DG unit

$$
\mathrm{P}_{\mathrm{DG}}^{\min } \leq \mathrm{P}_{\mathrm{DG}} \leq \mathrm{P}_{\mathrm{DG}}^{\max }
$$

$\mathrm{P}_{\mathrm{DG}}^{\min }$ minimum $\mathrm{DG}$ unit size

$\mathrm{P}_{\mathrm{DG}}^{\max }$ maximum $\mathrm{DG}$ unit size

From [25], the upper and lower limits can be set as follows:

$60 \leq \mathrm{P}_{\mathrm{DG}} \leq 3000$

Where the limits are in $\mathrm{kVA}, \mathrm{kVAr}$ and $\mathrm{KW}$ for type III, type II and type I DG respectively

D. Current constraints

$$
I i \leq \operatorname{Iimax} \text { for } \mathrm{i}=1,2, \ldots \mathrm{Nb}
$$

I $i$ represents the branch current of the $\mathrm{i}^{\text {th }}$ branch of the network consisting of $N_{b}$ number of branches. Iimax is the maximum permissible current flows through the $\mathrm{i}^{\text {th }}$ branch.

\subsection{Algorithm Steps}

a) Using Newton Rapshon method solve the load flow problem for the given test feeder and determine the system total power loss.

b) Initialize the random number of agents, set the iteration counter $=1$, set the values for minimum and maximum size of each DG unit, specify the number of DG units used.

c) Determine the real power los for generated population by performing load flow calculations.

d) Select the DG value with the lowest power losses as the current best solution.

e) If $\mathrm{p}<0.5$ and $\mathrm{A}>=1$, Update the position of the agents using (1) and (2).

f) Repeat step c.

g) Replace the current best solution with the updated values if the obtained results are lower than the current best solution. Otherwise go to step $h$.

h) If $\mathrm{p}<0.5$ and $\mathrm{A}<1$, Update the position of the agents using (8) and (9).

i) Repeat step c.

j) Replace the current best solution with the updated values if the obtained results are lower than the current best solution. Otherwise go to step $\mathrm{k}$

k) If $\mathrm{p}>=0.5$, update the position of the agents using (10).

l) Repeat step c.

m) Replace the current best solution with the updated values if the obtained results are lower than the current best solution. Otherwise go to step $n$.

n) Start the second iteration.

o) Repeat until the maximum number of iterations is performed and print the results.

\section{RESULTS AND ANALYSIS}

\subsection{The First Feeder}

The first test case is the 15 bus test feeder with the single line diagram shown in Figure 3 , the radial distribution feeder data is given in [25]. The load flow calculations applied to that test feeder before adding any DG units to the system. The power factor is 0.7 . The total apparent power is $1752 \mathrm{kVA}$. The reactive power losses and the total active power losses are $57.297 \mathrm{kVar}$ and $61.954 \mathrm{~kW}$ respectively, the minimum and maximum buses voltages range is $0.946 \leq \mathrm{Vi} \leq 1.0$ p.u.

The modified whale optimization algorithm (MWOA) technique is implemented and the DG units have been sized and placed in the system. The results seem to be superior regarding the real power loss which has been decreased enormously and the system voltage profile has been improved. 
Table 1 presents a comparison between the results of placing DG type I of different techniques. The superiority of the proposed method in this paper is clear. The technique results compared to ant lion optimization and traditional whale optimization algorithm showed that it produced the lowest real power losses with loss reduction percentage up to $38.68 \%$ which is presented in Figure 4 and the voltage profile is improved as the minimum voltage bus in pu in the system at bus number 13 is 0.966 .

Table 2 presents another comparison of results between placing different DG types. It is obvious that type III DG has the lowest system real power losses with reduction in power losses up to $64.85 \%$ and best enhanced voltage profile with minimum voltage bus $0.97 \mathrm{pu}$.

From Table 1 and Figure 4 it can be deduced that the proposed method has a superior performance regarding decreasing the real power loss and improving system voltage profile compared to other optimization techniques.

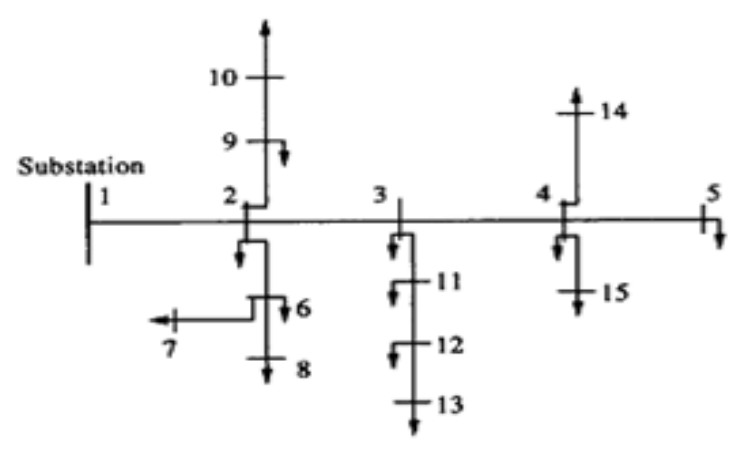

Figure 3. Single line diagram of 15 bus test system

\subsection{The Second Feeder}

The second tested feeder using the proposed modified whale optimization algorithm MWOA is the 33 bus system. It consists of main feeders and three laterals. The system single line diagram is shown in Figure 5. This test feeder has a total load of $3720 \mathrm{~kW}$ and $2300 \mathrm{kVAr}$ at a voltage level of $12.66 \mathrm{kV}$. The system data are presented in Ref. [14]. The configuration of the system before installing any DG unit is as follow: the real power loss in $\mathrm{kW}$ is 210.9 and the minimum bus voltage is 0.9038 . The results of using three different DG types (type I, type II and type III) applied to the test feeder are shown in Table 3. From Table 3, it is clear that DG type III installation results in the most reduction in real system power loss compared to the other DG types. Also the best minimum bus voltage for the tested feeder was achieved when installing DG type III.

Table 4 presents a comparison between different methods and techniques applied to this test feeder, it can be deduced that the proposed method has the lowest active power loss in Kw and the most improved system voltage profile. Figure 6 shows the enhancement in system voltage profile after adding DG type III. Also in Figure 7 the real power loss has the lowest value when the proposed technique is applied to the test feeder and compared to other methods including the classical whale optimization algorithm.

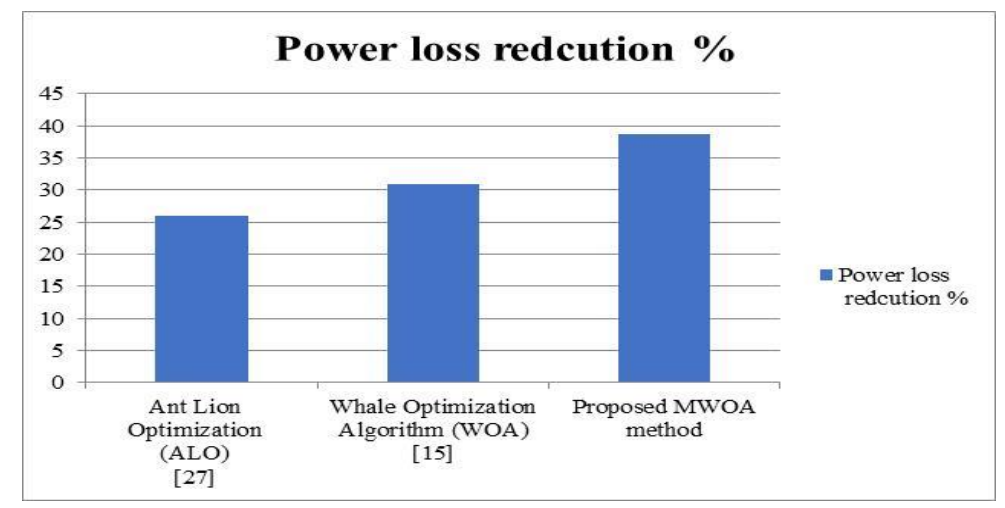

Figure 4. Power loss reduction percentage of 15 bus test system 
Table 1. Optimal Results of DG Type 1 Placement in 15-Bus Feeder

\begin{tabular}{|c|c|c|c|c|}
\hline \multirow[b]{2}{*}{ Parameter } & \multirow[b]{2}{*}{$\begin{array}{l}\text { B DeforeG } \\
\text { Placement }\end{array}$} & \multicolumn{3}{|c|}{ After Single DG Placement } \\
\hline & & $\begin{array}{l}\text { Ant Lion } \\
\text { Optimization } \\
\text { (ALO) } \\
\text { [27] }\end{array}$ & $\begin{array}{c}\text { Whale Optimization Algorithm } \\
\text { (WOA) } \\
{[15]}\end{array}$ & $\begin{array}{c}\text { Proposed } \\
\text { Method }\end{array}$ \\
\hline \multicolumn{2}{|c|}{$\begin{array}{c}\text { Year of technique publication } \\
\text { (Reference) }\end{array}$} & June 2017 & May 2017 & May 2018 \\
\hline $\begin{array}{c}\text { Final real power } \\
\operatorname{loss}(\mathrm{kW})\end{array}$ & 61.95 & 45.803 & 42.818 & 37.988 \\
\hline $\begin{array}{l}\text { Final reactive power } \\
\text { loss (KVAR) }\end{array}$ & 57.29 & 41.88 & 37.97 & 34 \\
\hline \multicolumn{2}{|c|}{ Loss Reduction \% for real power losses } & $26 \%$ & $30.88 \%$ & $38.68 \%$ \\
\hline Minimum Bus Voltage & 0.94 & 0.952 & 0.959 & 0.966 \\
\hline \multicolumn{2}{|c|}{ DG size $(\mathrm{KW})$} & 675.24 & 673.86 & 948.29 \\
\hline \multicolumn{2}{|c|}{ DG location } & 6 & 15 & 3 \\
\hline
\end{tabular}

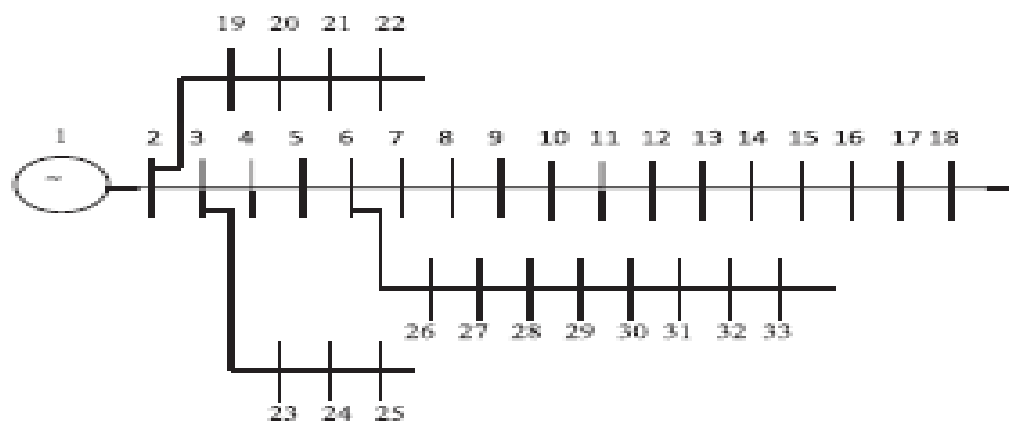

Figure 5. Single line diagram of 33-bus test system

Table 2. Optimal Results 15 Bus Feeder with DG Type 1, Type 2, and Type 3

\begin{tabular}{ccccc}
\hline & B DeforeG & & After Single DG Placement \\
Parameter & Placement & $\begin{array}{c}\text { DG Type I } \\
\text { Size in KW }\end{array}$ & $\begin{array}{c}\text { DG Type II } \\
\text { Size in KVAR }\end{array}$ & $\begin{array}{c}\text { Size in KVA III } \\
\text { Power factor 0.9 lag }\end{array}$ \\
\hline $\begin{array}{c}\text { Final real power } \\
\text { loss(kW) }\end{array}$ & 61.95 & 37.988 & 37.221 & 21.773 \\
$\begin{array}{c}\text { Final reactive power } \\
\text { loss (KVAR) }\end{array}$ & 57.29 & 34 & 33 & 18.29 \\
$\begin{array}{c}\text { Loss Reduction \% for real power losses } \\
\text { Minimum Bus Voltage }\end{array}$ & 0.94 & $38.68 \%$ & $39.92 \%$ & $64.85 \%$ \\
DG size & & 0.966 & 0.965 & 0.97 \\
DG location & & 948.29 & 963.4 & 1040.14 \\
\end{tabular}

Table 3. Optimal Results 33 Bus Feeder with DG Type 1, Type 2, and Type 3

\begin{tabular}{|c|c|c|c|c|}
\hline \multirow[b]{2}{*}{ Parameter } & \multirow[b]{2}{*}{$\begin{array}{l}\text { B DeforeG } \\
\text { Placement }\end{array}$} & \multicolumn{3}{|c|}{ After Single DG Placement } \\
\hline & & $\begin{array}{l}\text { DG Type I } \\
\text { Size in KW }\end{array}$ & $\begin{array}{c}\text { DG Type II } \\
\text { Size in KVAR }\end{array}$ & $\begin{array}{c}\text { DG Type III } \\
\text { Size in KVA } \\
\text { Power factor } 0.9 \text { lag }\end{array}$ \\
\hline $\begin{array}{c}\text { Final real power } \\
\operatorname{loss}(\mathrm{kW})\end{array}$ & 210.9 & 103.94 & 143.588 & 64.34 \\
\hline $\begin{array}{c}\text { Final reactive power } \\
\text { loss (KVAR) }\end{array}$ & 143.03 & 75 & 96 & 50 \\
\hline \multicolumn{2}{|c|}{ Loss Reduction $\%$ for real power losses } & 50.72 & 31.91 & 69.49 \\
\hline Minimum Bus Voltage & 0.9038 & 0.954 & 0.926 & 0.968 \\
\hline \multicolumn{2}{|c|}{ DG size } & 2575.35 & 1252.53 & 3000 \\
\hline \multicolumn{2}{|c|}{ DG location } & 6 & 30 & 6 \\
\hline
\end{tabular}


Table 4. Optimal Results of DG Type 1, Placement in 33 Bus Feeder

\begin{tabular}{|c|c|c|c|c|c|}
\hline \multirow[b]{2}{*}{ Parameter } & \multirow[b]{2}{*}{$\begin{array}{l}\text { Before DG } \\
\text { Placement }\end{array}$} & \multicolumn{4}{|c|}{ After Single DG Placement } \\
\hline & & $\begin{array}{c}\text { Backtracking } \\
\text { Search Algorithm } \\
\text { (BSOA) } \\
{[13]} \\
\end{array}$ & $\begin{array}{c}\text { Stud Krill Herd } \\
\text { Algorithm } \\
\text { (SKHA) } \\
{[17]} \\
\end{array}$ & $\begin{array}{c}\text { Whale Optimization } \\
\text { Algorithm } \\
\text { (WOA) } \\
{[15]}\end{array}$ & $\begin{array}{c}\text { Proposed } \\
\text { Method }\end{array}$ \\
\hline \multicolumn{2}{|c|}{$\begin{array}{c}\text { Year of technique publication } \\
\text { (Reference) }\end{array}$} & 2015 & 2017 & May 2017 & May 2018 \\
\hline $\begin{array}{l}\text { Final real power } \\
\operatorname{loss}(\mathrm{kW})\end{array}$ & 210.9 & 118.12 & 111.01 & 125.161 & 103.94 \\
\hline $\begin{array}{l}\text { Final reactive } \\
\text { power loss } \\
\text { (KVAR) }\end{array}$ & 143.03 & - & 81.71 & 89.28 & 75 \\
\hline \multicolumn{2}{|c|}{ Loss Reduction $\%$ for real power losses } & 44.01 & 47.36 & 40.65 & 50.72 \\
\hline $\begin{array}{l}\text { Minimum Bus } \\
\text { Voltage }\end{array}$ & 0.9038 & 0.9441 & 0.9424 & 0.9272 & 0.954 \\
\hline \multicolumn{2}{|c|}{ DG size $(\mathrm{KW})$} & 1857.5 & 2590 & 1542.67 & 2575 \\
\hline \multicolumn{2}{|c|}{ DG location } & 8 & 6 & 30 & 6 \\
\hline
\end{tabular}

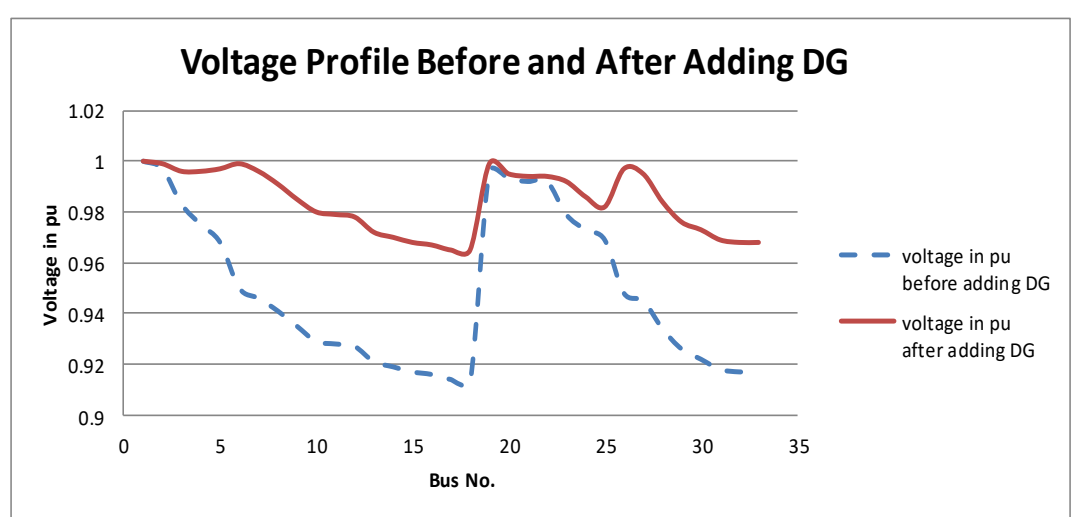

Figure 6. The effect of installing DG type III on system voltage profile

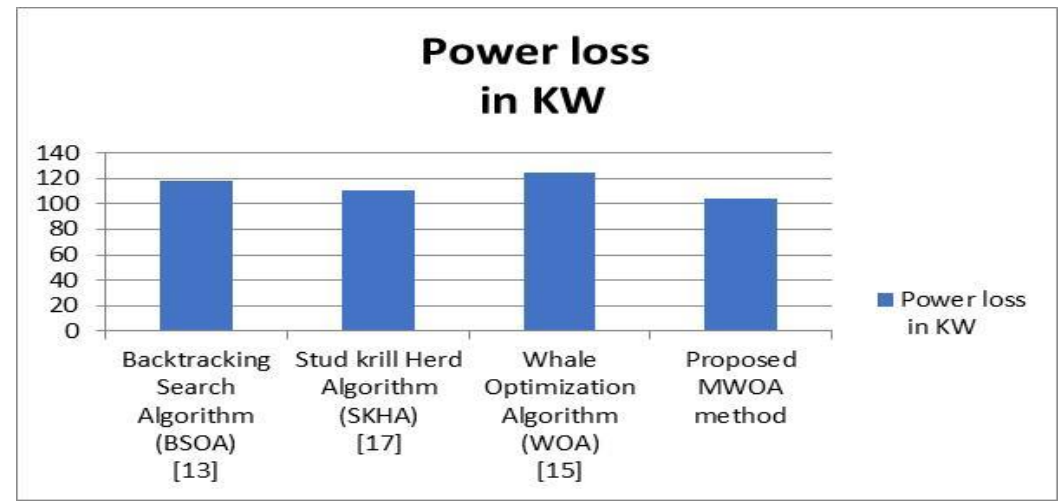

Figure 7. Results of system power loss reduction in $\mathrm{kW}$ of 33- bus test system

\section{CONCLUSION}

In this paper, a modified whale optimization algorithm has been successfully implemented for optimal location and sizing of DG units type I, type II and type III in various distribution test systems. The designed problem has been formulated as an optimization task with computing system power losses and enhancing system voltage profile. The effectiveness of the proposed technique is presented by using different test systems. The results have been compared regarding using different DG types and also with those obtained using other optimization methods. It is clear from the comparison that the proposed optimization method provides a superior performance in terms of system real power losses and improving system voltage profile. 


\section{REFERENCES}

[1] Muhamad Najib Kamarudin et al.,"Optimal sizing and location of distributed generation for loss minimization using firefly algorithm," Indonesian Journal of Electrical Engineering and Computer Science, Vol. 14, No. 1, pp. 421-427, April 2019.

[2] Mogaligunta Sankaraiah et al.,"GWO Based Optimal Reactive Power Coordination of DFIG, ULTC and Capacitors," Indonesian Journal of Electrical Engineering and Computer Science, Vol. 11, No. 3, pp. 805-813, September 2018.

[3] Mohamad Khairuzzaman Mohamad Zamani et al., "Gravitational Search Algorithm Based Technique for Voltage Stability Improvement," Indonesian Journal of Electrical Engineering and Computer Science, Vol. 9, No. 1, pp. 123-130, January 2018.

[4] Adam Hirsch et al., "Microgrids: A review of technologies, key drivers, and outstanding issues," Renewable and Sustainable Energy Reviews, vol.90, pp. 402-411, 2018.

[5] G.Pepermans et al., "Distributed generation: definition, benefits and issue," Energy Policy, vol.33 (6), pp. 787-798, April 2005.

[6] N. Mithulananthan et al.,"Distributed generator placement in power distribution system using genetic algorithm to reduce losses,"TIJSAT, vol.9 (3), pp. 55-62, 2004.

[7] P.S. Georgilakis and N.D. Hatziargyriou, "Optimal distributed generation placement in power distribution networks: models, methods and future research, " IEEE Transcation Power Systems, vol.28 (3), pp.3420-3428, 2013.

[8] Naresh Acharya et al., "An analytical approach for DG allocation in primary distribution network," Electrical Power and Energy Systems, vol.28, pp. 69-678, 2006.

[9] Willis HL and Scott WG., "Distributed power generation: planning and evaluation," New York: Marcel Dekker, 2000.

[10] Ackerman T et al.,"Distributed generation: a definition," Electrical Power System Resources, vol.57, pp.195-204, 2001.

[11] P. Dinakara Prasad Reddy et al.,"Application of flower pollination algorithm for optimal placement and sizing of distributed generation in distribution systems," Journal of Electrical System Information and Technology, vol.3, pp. 14-22, 2016.

[12] E.S. Ali et al.,"Ant Lion Optimization Algorithm for optimal location and sizing of renewable distributed generations," Renewable Energy, vol.101, pp. 1311-1324, 2017.

[13] A. El-Fergany et al.,"Optimal allocation of multi-type distributed generators using Backtracking search optimization algorithm," International Journal of Electrical Power Energy System, vol.64, pp. 1197-1205, 2015.

[14] D. Rama Prabha and T. Jayabarathi, "Optimal placement and sizing of multiple distributed generating units in distribution networks by invasive weed optimization algorithm," Ain Shams Engineering Journal, vol.7, pp. 683-694, 2016.

[15] P. Dinakara Prasad Reddy et al.,"Optimal renewable resources placement in distribution networks by combined power loss index and whale optimization algorithms, "Journal of Electrical Systems and Information Technology, vol.173, pp. 1-18, 2017.

[16] V.V.S.N Murty and Ashwani Kuma, "Mesh distribution system analysis in presence of distributed generation with time varying load model," International Journal of Electrical Power Energy System, vol.62, pp. 836-854, 2014.

[17] S.A. ChithraDevi et al.,"Stud Krill herd Algorithm for multiple DG placement and sizing in a radial distribution system," Engineering Science and Technology, an International Journal, vol.20, pp. 748-759, 2017.

[18] Ketfi Nadhir et al.,"Distributed generation and location and size determination to reduce power losses of a distribution feeder by Firefly Algorithm," International Journal of Advanced Science and Technology, vol. 56, pp. 61-72, 2013.

[19] Attia El-Fergany, "Multi-objective allocation of multi-type distributed generators along distribution networks using backtracking search algorithm and fuzzy expert rules," Electrical Power Components and Systems, vol. 44, pp. 252-267, 2016.

[20] D. Rama Prabha et al.,"Optimal location and sizing of distributed generation unit using intelligent water drop algorithm," Sustainable Energy Technologies and Assessments, vol. 11, pp.106-113,2015.

[21] U. Sultana et al.,"Grey wolf optimizer based placement and sizing of multiple distributed generation in the distribution system," Energy, vol.111, pp.525-536, 2016.

[22] Seyedali Mirjalili and Andrew Lewis,"The Whale Optimization Algorithm, "Advances in Engineering Software vol.95, pp. 51-67, 2016.

[23] D.B. Prakash and C. Lakshminarayana,"Optimal siting of capacitors in radial distribution network using Whale Optimization Algorithm," Alexandria Engineering Journal, vol.56, pp.499-509, 2017.

[24] Hongping Hu et al.,"A whale optimization algorithm with inertia weight," WSEAS Transactions on Computers, Vol. 15, pp. 319-326, 2016.

[25] M. E. Baran and F. F.Wu,"Optimal Sizing of Capacitors Placed on a Radial Distribution System," IEEE Trans. on Power Delivery, Vol. 4, No.1, pp.735-743, 1989.

[26] D. Das et al.,"Simple and efficient method for load flow solution of radial distribution networks," International Journal. Electrical. Power \& Energy System, vol.17, pp. 335-346, 1995.

[27] A.Y. Abdelaziz et al.,"Distribution Systems Reconfiguration using a modified particle swarm optimization algorithm", Electric Power Systems Research, vol.79, pp. 1521-1530, 2009. 


\section{BIOGRAPHIES OF AUTHORS}

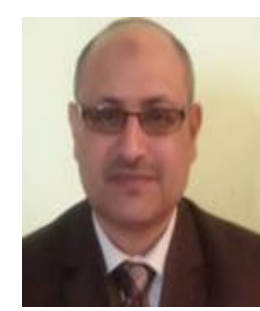

Received the B.Sc. and M.Sc. degrees in electrical engineering from Ain Shams University, Egypt, in 1985 and 1990, respectively, and the Ph.D. degree in electrical engineering according to the channel system between Ain Shams University, Egypt, and Brunel University, U.K., in 1996. He is currently a Professor of electrical power engineering at Ain Shams University. Dr. Abdelaziz is the chair of IEEE Education Society chapter in Egypt, senior editor of Ain Shams Engineering Journal, editor of Electric Power Components \& Systems Journal, editorial board member, associate editor and editorial advisory board member of several international journals and conferences. He is also a member in IET and the Egyptian Sub-Committees of IEC and CIGRE'. He has been awarded many prizes for distinct researches and for international publishing from Ain Shams University, Egypt. He has authored or coauthored more than 320 refereed journal and conference papers in his research areas which include the applications of artificial intelligence, evolutionary and heuristic optimization techniques to power system operation, planning, and control.

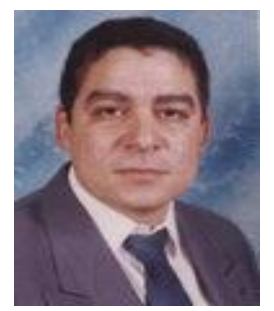

Was born in Egypt in 1964. He received the B. Sc. and M.Sc. degrees in electrical engineering from Ain Shams University, Cairo, Egypt, and the Ph.D. degree in electrical engineering from Ain Shams University with joint supervision from Dalhousie University, Halifax, NS, Canada, in 2002. He is currently a Professor in the Department of Electric Power and Machines, Ain Shams University. His research interests include power system analysis, power system protection, and applications of $\mathrm{AI}$ in power systems.

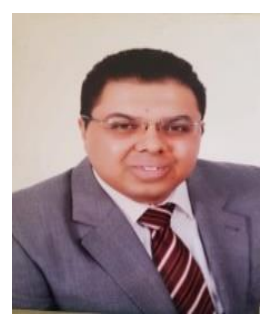

Was born in Egypt in 1986. He received the B.Sc. and M.Sc. degrees in electrical engineering from Ain Shams University, Egypt, in 2008 and 2014, respectively and is currently registered as a Ph.D. researcher in electrical engineering in the same university. Since 2009, he has been working for the Arab Contractors in Egypt and currently occupies the position as a senior electrical power system design and tender engineer. Through this position, he has participated in many local, regional and African projects about the design and tender studies of different power systems in buildings and water stations with the different national and international organizations. 